\title{
Gram-Negative Bloodstream Infection: Implications of Antimicrobial Resistance on Clinical Outcomes and Therapy
}

\author{
Majdi N. Al-Hasan 1,2 (1) \\ 1 Department of Medicine, Division of Infectious Diseases, University of South Carolina School of Medicine, \\ Columbia, SC 29209, USA; majdi.alhasan@uscmed.sc.edu; Tel.: +1-803-540-1062; Fax: +1-803-540-1079 \\ 2 Department of Medicine, Division of Infectious Diseases, Prisma Health-Midlands, Columbia, SC 29203, USA
}

Received: 2 December 2020; Accepted: 16 December 2020; Published: 18 December 2020

The age- and sex-adjusted incidence rate of Gram-negative bloodstream infection (GN-BSI) is 84.5 per 100,000 person-years in the USA [1]. Recent advancements in diagnostics as well as clinical and antimicrobial management have reduced the overall case-fatality of GN-BSI to $12-15 \%[2,3]$. GN-BSI accounts for 279,000 cases and 33,500-41,900 deaths annually in the USA based on the current population. Source control and early initiation of appropriate empirical antimicrobial therapy remain the most important modifiable variables for improving the clinical outcomes of patients with GN-BSI [4-6]. However, increasing antimicrobial resistance rates of Gram-negative bloodstream isolates continues to pose serious challenges to patients, clinicians, and researchers.

This Special Issue on Gram-negative bloodstream infections in Antibiotics highlights the impact of antimicrobial resistance to first-line agents on the clinical outcomes and antimicrobial management of GN-BSI. The authors of the studies in this Special Issue examine the effectiveness of different antimicrobial treatment strategies in BSI due to Gram-negative bacteria with various beta-lactam resistance mechanisms. They assess the implications of fluoroquinolone and beta-lactam resistance on the clinical outcomes of patients with GN-BSI. This is particularly important given that beta-lactams and fluoroquinolones represent the cornerstones of empirical and definitive antimicrobial therapy for GN-BSI, respectively [7-9]. The recently proposed definition of difficult-to-treat resistance (DTR) by Kadri and colleagues further enhances the importance of resistance to first-line agents (e.g., beta-lactams and fluoroquinolones) [2,3,7]. Review articles in the Special Issue discuss the role of novel antimicrobial agents in the treatment of BSI due to Gram-negative bacteria with DTR. The results of many investigations in this Special Issue have major implications for antimicrobial stewardship practices.

Previous studies reported that patients with fluoroquinolone-resistant GN-BSI had higher mortality and longer hospital length of stay than those with fluoroquinolone-susceptible bloodstream isolates $[10,11]$. Notably, most fluoroquinolone-resistant bloodstream isolates, particularly Escherichia coli ST131, carried antimicrobial resistance genes to other antimicrobial classes and were hence considered multi-drug resistant (MDR) [11,12]. Suzuki and colleagues went one step further and demonstrated that fluoroquinolone resistance even in the absence of concomitant phenotypic beta-lactam resistance still predicted higher mortality in BSI due to E. coli and Klebsiella species [13]. This remarkable work was the first to show the negative impacts of isolated fluoroquinolone resistance on patients' clinical outcomes [13]. In this Special Issue of Antibiotics, Suzuki and colleagues demonstrate that patients with hospital-onset E. coli and Klebsiella species BSI due to either fluoroquinolone or extended-spectrum cephalosporin-resistant isolates have considerably longer hospital length of stay than those with BSI due to susceptible isolates [14]. The results of this multicenter matched cohort study argue that investments in antimicrobial stewardship and infection prevention are clearly justified based 
on the massive clinical and financial burden of fluoroquinolone and extended-spectrum cephalosporin resistance on the healthcare system in the USA [14].

To ensure maximum efficacy, the Clinical Laboratory Standards Institute (CLSI) followed the recommendations of the United States Committee on Antimicrobial Susceptibility Testing (USCAST) and lowered the minimum inhibitory concentration (MIC) susceptibility breakpoints of fluoroquinolones for Enterobacterales and nonfermenting Gram-negative bacilli [15]. This change has major implications on antimicrobial management, since fluoroquinolones remain by far the most commonly prescribed agents for definitive therapy of GN-BSI [8,9]. Shealy and colleagues precisely quantified the potential impacts of changing fluoroquinolone susceptibility breakpoints in Gram-negative bloodstream isolates [16]. An additional 5\% and 8\% of patients with BSI due to Enterobacterales and Pseudomonas aeruginosa, respectively, would not be eligible for fluoroquinolone definitive therapy after the implementation of the new CLSI susceptibility breakpoints [16]. The study calls for clinical pharmacokinetic and pharmacodynamic investigations to optimize the dosing of oral beta-lactams in this patient population and development of novel oral antimicrobial agents to fill this gap [16].

The MERINO trial provided much-needed clarity on the most appropriate antimicrobial therapy for BSI due to extended spectrum beta-lactamase (ESBL)-producing Enterobacterales [17]. However, antimicrobial management of BSI due to chromosomally mediated AmpC-producing Enterobacterales (CAE) remains controversial [18]. Previous literature demonstrated the effectiveness of cefepime in comparison to carbapenems for the treatment of BSI due to these bacteria [19]. In this Special Issue, Derrick and colleagues suggest that ceftriaxone may be a treatment option in patients with low-inoculum BSI due to Enterobacter cloacae and other CAE [20]. This is conceivable, since low-inoculum sources of GN-BSI are associated with lower mortality [21,22]. This multicenter cohort study is the first to report the effectiveness of ceftriaxone for BSI due to CAE [20]. The study has major antimicrobial stewardship implications, since it allows de-escalation of antimicrobial therapy from carbapenems or cefepime to ceftriaxone in patients with uncomplicated CAE BSI secondary to urinary tract source without obstruction or central venous catheter infection after catheter removal [20]. The results should not be extrapolated to patients with more complex sources of GN-BSI, such as pulmonary infections or multi-loculated intra-abdominal abscesses, due to the increased risk of resistance development and mortality [21-24].

The Special Issue includes another study that has huge antimicrobial stewardship indications. Lee and colleagues are the first to report the effectiveness of cefazolin definitive therapy for community-onset BSI due to susceptible Enterobacterales [25]. Data have been lacking on this topic due to the frequent updates to cefazolin MIC susceptibility breakpoints by various agencies. The results of this matched cohort study encourage antimicrobial stewardship practice of the de-escalation of antimicrobial therapy from broad-spectrum agents to intravenous cefazolin in patients with cefazolin-susceptible Enterobacterales BSI based on contemporary CLSI breakpoints [25]. This is crucial, since early de-escalation of antimicrobial therapy reduces the risk of Clostridioides difficile infection in these patients [26].

While original clinical research studies dominate this Special Issue, it has a fair share of high-quality basic science and translational research articles. Advancements of whole-genome sequencing (WGS) techniques have contributed to a better understanding of antimicrobial resistance mechanisms and improvement of antimicrobial therapy. Shelenkov and colleagues use WGS to define antimicrobial resistance mechanisms and virulence profiling of predominantly MDR Klebsiella pneumoniae isolates in the Russian Federation [27]. The incorporation and visualization of genotypic and phenotypic resistance patterns on one platform represents phenomenal work and sets a high standard for future investigations. Moreover, the authors describe two new multi-locus sequence typing (MLST)-based sequence types of K. pneumoniae [27]. In the second basic science article of this Special Issue, Fokam and colleagues examine iron chelation in murine models of systemic inflammation induced by Gram-positive and Gram-negative bacterial toxins [28]. This is a timely topic, given the recent development of cefiderocol, 
a novel antimicrobial agent for the treatment of Gram-negative bacteria with DTR that utilizes the iron transport system.

In addition to original research studies, the Special Issue includes two comprehensive reviews of the management of Gram-negative bacterial infections. Bassetti and colleagues summarize various beta-lactam resistance mechanisms and discuss antimicrobial treatment options for BSI due to Gram-negative bacteria with DTR [29]. The authors objectively review novel antimicrobial agents, examine the activity of these agent for various antimicrobial resistance mechanisms, and provide insight into the role of these agents in clinical practice [29]. Since the respiratory tract is one of the most common sources of Gram-negative bacteria with DTR, Martin-Loeches summarizes current concepts in the management of community-acquired and ventilator-associated pneumonia in intensive care units [30]. This is a timely review as well, given recent updates to international management guidelines on these two topics [31,32].

We hope this Special Issue of Antibiotics will enhance the knowledge and understanding of researchers and practitioners, improve clinical practice, and incite future innovative basic science, translational, and clinical research on antimicrobial resistance and GN-BSI.

Funding: This manuscript received no funding.

Acknowledgments: I would like to thank all of the authors who contributed these high-quality articles towards this Special Issue and the outstanding editorial staff of Antibiotics who made publication of this Special Issue possible.

Conflicts of Interest: The author declares no conflict of interest.

\section{References}

1. Al-Hasan, M.N.; Eckel-Passow, J.E.; Baddour, L.M. Recurrent Gram-negative bloodstream infection: A 10-year population-based cohort study. J. Infect. 2010, 61, 28-33. [CrossRef] [PubMed]

2. Kadri, S.S.; Adjemian, J.; Lai, Y.L.; Spaulding, A.B.; Ricotta, E.; Prevots, D.R.; Palmore, T.N.; Rhee, C.; Klompas, M.; Dekker, J.P.; et al. National Institutes of Health Antimicrobial Resistance Outcomes Research Initiative (NIH-ARORI). Difficult-to-treat resistance in Gram-negative bacteremia at 173 US hospitals: Retrospective cohort analysis of prevalence, predictors, and outcome of resistance to all first-line agents. Clin. Infect. Dis. 2018, 67, 1803-1814. [CrossRef] [PubMed]

3. Kadri, S.S.; Lai, Y.L.E.; Ricotta, E.E.; Strich, J.R.; Babiker, A.; Rhee, C.; Klompas, M.; Dekker, J.P.; Powers, J.H., III; Danner, R.L.; et al. External validation of difficult-to-treat resistance prevalence and mortality risk in Gram-negative bloodstream infection using electronic health record data from 140 US hospitals. Open Forum Infect. Dis. 2019, 6, ofz110. [CrossRef]

4. Kadri, S.S.; Lai, Y.L.; Warner, S.; Strich, J.R.; Babiker, A.; Ricotta, E.E.; Demirkale, C.Y.; Dekker, J.P.; Palmore, T.N.; Rhee, C.; et al. Forming the National Insititutes of Health Antimicrobial Resistance Outcomes Research Initiative (NIH-ARORI). Inappropriate empirical antibiotic therapy for bloodstream infections based on discordant in-vitro susceptibilities: A retrospective cohort analysis of prevalence, predictors, and mortality risk in US hospitals. Lancet Infect. Dis. 2020. [CrossRef]

5. Cain, S.E.; Kohn, J.; Bookstaver, P.B.; Albrecht, H.; Al-Hasan, M.N. Stratification of the impact of inappropriate empirical antimicrobial therapy for Gram-negative bloodstream infections by predicted prognosis. Antimicrob. Agents Chemother. 2015, 59, 245-250. [CrossRef] [PubMed]

6. Battle, S.E.; Kohn, J.; Bookstaver, B.; Albrecht, H.; Al-Hasan, M.N. Association between inappropriate empirical antimicrobial therapy and hospital length of stay in Gram-negative bloodstream infections: Stratification by prognosis. J. Antimicrob. Chemother. 2017, 72, 299-304. [CrossRef] [PubMed]

7. Al-Hasan, M.N. Gram-negative bacteria with difficult-to-treat resistance: A moving target. Clin. Infect. Dis. 2020, ciaa384. [CrossRef]

8. Punjabi, C.; Tien, V.; Meng, L.; Deresinski, S.; Holubar, M. Oral fluoroquinolone or trimethoprimsulfamethoxazole vs. B-lactams as step-down therapy for Enterobacteriaceae bacteremia: Systematic review and meta-analysis. Open Forum Infect. Dis. 2019, 6, ofz364, Epub ahead of print. [CrossRef]

9. Al-Hasan, M.N.; Rac, H. Transition from intravenous to oral antimicrobial therapy in patients with uncomplicated and complicated bloodstream infections. Clin. Microbiol. Infect. 2020, 26, 299-306. [CrossRef] 
10. Lautenbach, E.; Metlay, J.P.; Bilker, W.B.; Edelstein, P.H.; Fishman, N.O. Association between fluoroquinolone resistance and mortality in Escherichia coli and Klebsiella pneumoniae infections: The role of inadequate empirical antimicrobial therapy. Clin. Infect. Dis. 2005, 41, 923-929.

11. Brigmon, M.M.; Bookstaver, P.B.; Kohn, J.; Albrecht, H.; Al-Hasan, M.N. Impact of fluoroquinolone resistance in Gram-negative bloodstream infections on healthcare utilization. Clin. Microbiol. Infect. 2015, 21, 843-849. [CrossRef] [PubMed]

12. Johnson, J.R.; Porter, S.; Thuras, P.; Castanheira, M. Epidemic emergence in the United States of Escherichia coli sequence type 131-H30 (ST131-H30), 2000 to 2009. Antimicrob. Agents Chemother. 2017, 61, e00732-17. [CrossRef] [PubMed]

13. Suzuki, H.; Perencevich, E.N.; Livorsi, D.J.; Alexander, B.; Beck, B.F.; Richardson, K.K.; Goto, M. Attributable mortality due to fluoroquinolone and extended-spectrum cephalosporin resistance in hospital-onset Escherichia coli and Klebsiella spp bacteremia: A matched cohort study in 129 Veterans Health Administration medical centers. Infect. Control Hosp. Epidemiol. 2019, 40, 928-931. [CrossRef] [PubMed]

14. Suzuki, H.; Perencevich, E.N.; Nair, R.; Livorsi, D.J.; Goto, M. Excess length of acute inpatient stay attributable to acquisition of hospital-onset Gram-negative bloodstream infection with and without antibiotic resistance: A multistate model analysis. Antibiotics 2020, 9, 96. [CrossRef]

15. USCAST. The National Antimicrobial Susceptibility Testing Committee for the United States. Quinolone In Vitro Susceptibility Test Interpretive Criteria Evaluations. Version 1.3. 2018. Available online: http: //www.uscast.org (accessed on 1 December 2020).

16. Shealy, S.C.; Brigmon, M.M.; Justo, J.A.; Bookstaver, P.B.; Kohn, J.; Al-Hasan, M.N. Impact of reappraisal of fluoroquinolone minimum inhibitory concentration susceptibility breakpoints in Gram-negative bloodstream isolates. Antibiotics 2020, 9, 189. [CrossRef]

17. Harris, P.N.A.; Tambyah, P.A.; Lye, D.C.; Mo, Y.; Lee, T.H.; Yilmaz, M.; Alenazi, T.H.; Arabi, Y.; Falcone, M.; Bassetti, M.; et al. Effect of piperacillin-tazobactam vs meropenem on 30-day mortality for patients with $E$ coli or Klebsiella pneumoniae bloodstream infection and ceftriaxone resistance: A randomized clinical trial. JAMA 2018, 320, 984-994. [CrossRef]

18. Mizrahi, A.; Delerue, T.; Morel, H.; Le Monnier, A.; Carbonnelle, E.; Pilmis, B.; Zahar, J.R.; On Behalf the Saint-Joseph/Avicenna Study Group. Infections caused by naturally AmpC-producing Enterobacteriaceae: Can we use third-generation cephalosporins? A narrative review. Int. J. Antimicrob. Agents 2020, 55, 105834. [CrossRef]

19. Hilty, M.; Sendi, P.; Seiffert, S.N.; Droz, S.; Perreten, V.; Hujer, A.M.; Bonomo, R.A.; Mühlemann, K.; Endimiani, A. Characterisation and clinical features of Enterobacter cloacae bloodstream infections occurring at a tertiary care university hospital in Switzerland: Is cefepime adequate therapy? Int. J. Antimicrob. Agents 2013, 41, 236-249. [CrossRef]

20. Derrick, C.; Bookstaver, P.B.; Lu, Z.K.; Bland, C.M.; King, S.T.; Stover, K.R.; Rumley, K.; MacVane, S.H.; Swindler, J.; Kincaid, S.; et al. Multicenter, observational cohort study evaluating third-generation cephalosporin therapy for bloodstream infections secondary to Enterobacter, Serratia, and Citrobacter species. Antibiotics 2020, 9, 254. [CrossRef]

21. Al-Hasan, M.N.; Lahr, B.D.; Eckel-Passow, J.E.; Baddour, L.M. Predictive scoring model of mortality in Gram-negative bloodstream infection. Clin. Microbiol. Infect. 2013, 19, 948-954. [CrossRef]

22. Al-Hasan, M.N.; Juhn, Y.J.; Bang, D.W.; Yang, H.J.; Baddour, L.M. External validation of bloodstream infection mortality risk score in a population-based cohort. Clin. Microbiol. Infect. 2014, 20, 886-891. [CrossRef] [PubMed]

23. Kaye, K.S.; Cosgrove, S.; Harris, A.; Eliopoulos, G.M.; Carmeli, Y. Risk factors for emergence of resistance to broad-spectrum cephalosporins among Enterobacter spp. Antimicrob. Agents Chemother. 2001, 45, 2628-2630. [CrossRef] [PubMed]

24. Kang, C.I.; Kim, S.H.; Park, W.B.; Lee, K.D.; Kim, H.B.; Oh, M.D.; Kim, E.C.; Choe, K.W. Bloodstream infections caused by Enterobacter species: Predictors of 30-day mortality rate and impact of broad-spectrum cephalosporin resistance on outcome. Clin. Infect. Dis. 2004, 39, 812-818. [CrossRef] [PubMed]

25. Lee, C.-C.; Lee, C.-H.; Chen, P.-L.; Hsieh, C.-C.; Tang, H.-J.; Ko, W.-C. Definitive cefazolin treatment for community-onset Enterobacteriaceae bacteremia based on the contemporary CLSI breakpoint: Clinical experience of a medical center in Southern Taiwan. Antibiotics 2019, 8, 216. [CrossRef] 
26. Seddon, M.M.; Bookstaver, P.B.; Justo, J.A.; Kohn, J.; Rac, H.; Haggard, E.; Mediwala, K.N.; Dash, S.; Al-Hasan, M.N. Role of early de-escalation of antimicrobial therapy on risk of Clostridioides difficile infection following Enterobacteriaceae bloodstream infections. Clin. Infect. Dis. 2019, 69, 414-420. [CrossRef]

27. Shelenkov, A.; Mikhaylova, Y.; Yanushevich, Y.; Samoilov, A.; Petrova, L.; Fomina, V.; Gusarov, V.; Zamyatin, M.; Shagin, D.; Akimkin, V. Molecular typing, characterization of antimicrobial resistance, virulence profiling and analysis of whole-genome sequence of clinical Klebsiella pneumoniae isolates. Antibiotics 2020, 9, 261. [CrossRef]

28. Fokam, D.; Dickson, K.; Kamali, K.; Holbein, B.; Colp, P.; Stueck, A.; Zhou, J.; Lehmann, C. Iron chelation in murine models of systemic inflammation induced by Gram-positive and Gram-negative toxins. Antibiotics 2020, 9, 283. [CrossRef]

29. Bassetti, M.; Vena, A.; Sepulcri, C.; Giacobbe, D.R.; Peghin, M. Treatment of bloodstream infections due to Gram-negative bacteria with difficult-to-treat resistance. Antibiotics 2020, 9, 632. [CrossRef]

30. Martin-Loeches, I. Current concepts in community and ventilator associated lower respiratory tract infections in ICU patients. Antibiotics 2020, 9, 380. [CrossRef]

31. Kalil, A.C.; Metersky, M.L.; Klompas, M.; Muscedere, J.; Sweeney, D.A.; Palmer, L.B.; Napolitano, L.M.; O'Grady, N.P.; Bartlett, J.G.; Carratalà, J.; et al. Management of adults with hospital-acquired and ventilator-associated pneumonia: 2016 clinical practice guidelines by the Infectious Diseases Society of America and the American Thoracic Society. Clin. Infect. Dis. 2016, 63, e61-e111. [CrossRef]

32. Metlay, J.P.; Waterer, G.W.; Long, A.C.; Anzueto, A.; Brozek, J.; Crothers, K.; Cooley, L.A.; Dean, N.C.; Fine, M.J.; Flanders, S.A.; et al. Diagnosis and treatment of adults with community-acquired pneumonia. An official clinical practice guideline of the American Thoracic Society and Infectious Diseases Society of America. Am. J. Respir. Crit. Care Med. 2019, 200, e45-e67. [CrossRef] [PubMed]

Publisher's Note: MDPI stays neutral with regard to jurisdictional claims in published maps and institutional affiliations. 